Brit. J. vener. Dis. (1957), 33, 34.

\title{
GONOCOCCAL INFECTION IN TEEN-AGED GIRLS AND MATURE WOMEN*
}

\author{
BY \\ LEOPOLD Z. GOLDSTEIN \\ Associate in Obstetrics and Gynaecology, Albert Einstein Medical Centre, Philadelphia, Pa., U.S.A.
}

The spread of gonorrhoea must be prevented by investigating, tracing, and treating the female sexual contacts of men treated for this infection. Its obvious clinical nature in males and the simple test available for diagnosis are the factors concerned in this method of control. In the main, the epidemiological control of venereal disease is a major function of our nation-wide public health clinics. Gonorrhoea in women and girls has become an increasingly important public health problem and one of diminishing interest to general medical practitioners. This lack of interest may be attributed partly to the almost perfect therapeutic effects of the now available antibiotic drugs on this venereal disease as well as on syphilis. Despite the curative efficacy of antibiotics, the numerous cases of gonorrhoea reported by physicians and clinics indicate the continued seriousness of the problem. Although more cases of gonorrhoea have been reported in males than in females, the incidence of the disease in the latter is still significantly high. For instance, the reports from all sources to the U.S. Department of Health for the fiscal year ending July, 1955, list 239,787 cases in both sexes. According to race, there were 14,737 or 19 per cent. in the white or colour unknown, and 60,932 or 81 per cent. in non-white females.

Private physicians reported a total of 7,112 cases of gonorrhoea in females or only $9 \cdot 3$ per cent. It is difficult to determine the actual number of cases with gonorrhoea treated in private practice because many physicians lack interest in the management and control of venereal disease. Lentz and Beerman (1953) noted the declining number of cases of gonorrhoea reported from private practice in Philadelphia, and they indicated that many physicians may not be reporting a large proportion of their cases. Further, the difficulty in confirming by laboratory methods, even when available, the clinical diagnosis of gonococcal infection in women

\footnotetext{
* Received for publication September 27, 1956.
}

also affects the proper estimation of the incidence.

This paper is concerned with a clinical investigation of gonorrhoea in teen-aged girls (under 20 years of age) and in adult females. In a previous paper on this subject (Goldstein, 1955a), no differentiation was made between the age groups, although it was noted that adolescents comprised almost onethird of all females allegedly infected. I thought, therefore, that interesting clinical and microscopical findings concerning some aspects of the disease might be disclosed by analysing the data from the study in teen-agers. Another reason for this new survey is the increasing prominence emphasized by Donohue, Gleeson, Jenkins, and Price (1955) of the relationship of venereal disease in teen-agers to delinquency, tendency to crime, and other socio-economic problems. The clinical work was done in the Central Diagnostic Centre of the Section of Venereal Disease Control, Division of Preventive Medicine of the Philadelphia Department of Public Health. This clinic is centrally located and draws its patients from outlying districts of the city. However, most of the patients come from geographical areas of known low economic status.

\section{Material and Methods}

The clinical material consists of 538 females between the ages of 13 and 43 whom I examined between October, 1951, and July, 1953 because they were suspected of having gonorrhoea. All the adults and most of the girls were named as sexual contacts by men treated for acute urethritis caused in almost all cases by Neisseria gonorrhoeae. Some adolescents were referred for pelvic examination by public school authorities because they were suspected of being gonorrhoeal contacts. Others were brought to the clinic by their mothers because of symptoms such as profuse vaginal discharge, pelvic pain, or other genito-urinary complaints.

After registration and the recording of a brief gynaecological history, the patients were prepared for pelvic examination. The vagina and cervix were first inspected without the use of lubricating jelly on the speculum. Routine smears from the endocervical 
discharge were drawn from all patients for staining by Gram's method. Sterile cotton applicators were used to transfer the specimens of cervical material to tubes of peptone broth. The broth preparations were transported within 2 or 3 hrs to a central laboratory for transference to special media enriched with chocolate agar.

Special media and methods for the isolation - of Neisseria gonorrhoeae have been described in detail by Carpenter and eleven others (1949) and by Somerson, Rubin, Smith, and Morton (1955).

Wet smears of vaginal discharge were also examined if the presence of trichomonads or monilia was suspected from the appearance of the discharge. After the specimens were collected, a pelvic examination was performed and the clinical diagnosis recorded. Every registrant received a serological test for syphilis. If a patient was observed to have an external genital lesion or inguinal adenopathy, she was held for dark-field study and other tests for chancroid, lymphogranuloma venereum, or granuloma inguinale as indicated.

All patients who were identified as the sexual contacts of men who had been treated for gonorrhoea were treated with $1 \cdot 2$ million units aqueous penicillin. The antibiotic was given as a public health measure to prevent possible spread of the infection regardless of the pelvic findings. All contacts whose laboratory tests were positive for the Neisserian organism were re-examined a week later.

Though all the women investigated here were the sexual contacts named by men who showed clinical evidence of gonorrhoea, smears of their discharge later confirmed the diagnosis in about 85 to 90 per cent. of them. Since the female contacts are usually returned to the clinic for pelvic examination within 24 to $48 \mathrm{hrs}$ after they are identified, microscopical proof of the venereal disease in their sexual partners is not then available.

Classification of Clinical Material.-There were 491 (91.3 per cent.) non-white and $47(8.7$ per cent.) white contacts. Of these, there were 155 ( 28.8 per cent.) adolescents and $383(71 \cdot 2$ per cent.) adults. Fig. 1 shows the percentage distribution of all patients in age groups. An abrupt rise occurs in the number of contacts from 9.6 per cent. at the 13 - to 16 -year age group to 40 per

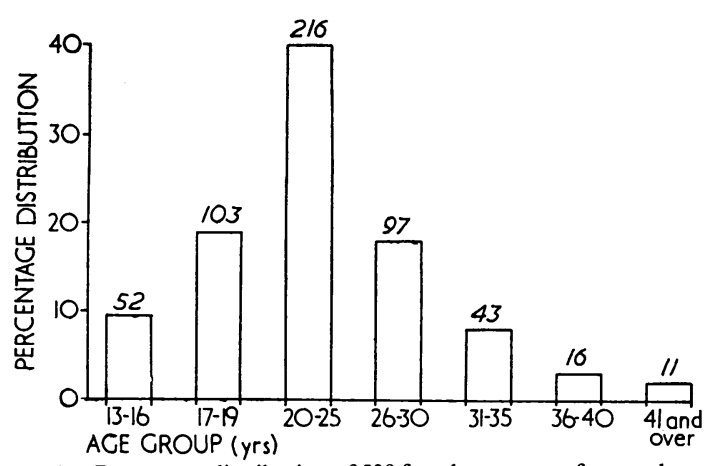

FIG. 1,-Percentage distribution of 538 female contacts of gonorrhoea. cent. at the 20- to 25-year age group. There is then a marked drop at the 26- to 30-year age group.

About two-thirds or 108 of the teen-agers were between 15 and 18 yrs old. Only twenty (13 per cent.) young contacts claimed they were married, either living with their husbands or separated, and 135 (87 .per cent.) were unmarried. Table I shows the marital status and data pertaining to pregnancies among the adolescents and the adults. Of the adults, $31 \cdot 6$ per cent. were unmarried. Twenty-nine ( 21.4 per cent.) of the unmarried teen-agers admitted pregnancies, and 62 (51 per cent.) of the older unmarried group had aborted or borne children. Of interest, too, is the discovery that at the time of registration, nine $(5 \cdot 8$ per cent.) of the teen-agers were pregnant, four married, and five unmarried.

\section{TABLE I}

MARITAL STATUS AND NUMBER OF PREGNANCIES IN 155 TEEN-AGERS AND 383 ADULTS

\begin{tabular}{|c|c|c|c|c|c|}
\hline \multirow[b]{2}{*}{ Group } & \multirow[b]{2}{*}{ Marital Status } & \multicolumn{2}{|c|}{ Cases } & \multicolumn{2}{|c|}{ Pregnancies } \\
\hline & & Number & $\begin{array}{c}\text { Per } \\
\text { cent. }\end{array}$ & Number & $\begin{array}{l}\text { Per } \\
\text { cent. }\end{array}$ \\
\hline $\begin{array}{l}\text { Teen- } \\
\text { agers } \\
\text { (155) }\end{array}$ & $\begin{array}{l}\text { Unmarried } \\
\text { Married or } \\
\text { Separated }\end{array}$ & $\begin{array}{r}135 \\
20\end{array}$ & $\begin{array}{l}87 \\
13\end{array}$ & $\begin{array}{l}29 \\
16\end{array}$ & $\begin{array}{l}22 \\
80\end{array}$ \\
\hline $\begin{array}{c}\text { Adults } \\
\text { (383) }\end{array}$ & $\begin{array}{l}\text { Unmarried } \\
\text { Married }\end{array}$ & $\begin{array}{l}121 \\
262\end{array}$ & $\begin{array}{l}31 \cdot 6 \\
68 \cdot 4\end{array}$ & $\begin{array}{r}62 \\
131\end{array}$ & $\begin{array}{l}49 \\
50\end{array}$ \\
\hline
\end{tabular}

\section{Results of Tests}

Results of the bacteriological tests are recorded in Table II. Neisseria gonorrhoeae were isolated by culture from the cervix in 81 contacts. Smears were positive in thirty additional cases in which negative reports of cultures were obtained or no information regarding cultures was available. These 111 (20.6 per cent.) contacts with positive cultures and/or smears were considered to be infected with gonorrhoea.

TABLE II

RESULTS OF TESTS

\begin{tabular}{|c|c|c|c|}
\hline \multirow{2}{*}{ Tests (Positive) } & \multicolumn{3}{|c|}{ Contacts } \\
\hline & Teen-agers & Adults & Total \\
\hline Cultures & 25 & 56 & $81^{*}$ \\
\hline $\begin{array}{cccc}\text { Smears only (Cultures negative or } \\
\text { not reported) } & \ldots & \ldots & \ldots\end{array}$ & 5 & 25 & 30 \\
\hline $\begin{array}{ccccc}\text { Total Positivet } & \text { (Cultures } & \text { and/or } \\
\text { Smears) } & \ldots & \ldots & \ldots & \ldots\end{array}$ & 30 & 81 & 111 \\
\hline Total Number Tested & 155 & 383 & 538 \\
\hline Percentage Positive in Total Tested & $19 \cdot 3$ & $21 \cdot 1$ & $20 \cdot 6$ \\
\hline
\end{tabular}

$* 81=16$ per cent. of 508 successful cultures.

† Both cultures and smears were positive in 9 teen-agers and 27 adults.

The distribution by cumulative percentage of all contacts and those with confirmed gonorrhoea is 
shown in Fig. 2. The curves indicate that 50 per cent. of the contacts and 50 per cent. of those with proved gonorrhoea were under 23 years of age. The curves of both groups run parallel with each other. The quartile horizontal line indicates that 19 per cent. of the contacts with this venereal disease had contracted it by the time they reached the age of 19 .

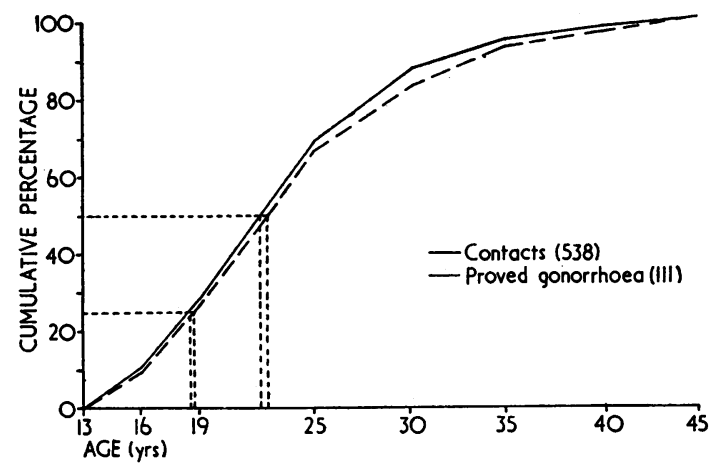

FIG. 2.-Cumulative percentage distribution of 538 contacts and confirmed gonorrhoea according to age.

Results of Serological Tests.-There were seven cases (4.7 per cent.) of syphilis among the adolescents. This compares with the detection of 46 cases $(12 \cdot 2)$ per cent.) of syphilis among the adults. Two teen-agers were infected with both syphilis and gonorrhoea.

\section{Results of Pelvic Examination}

Pelvic Lesions in Teen-agers.-The various pelvic abnormalties found in these girls are listed in Table III. In seventy $(45 \cdot 1$ per cent.), the cervix appeared clinically healthy and the pelvic organs were normal on bimanual examination. In 24 girls,

TABLE III

PELVIC CONDITIONS IN TEEN-AGED CONTACTS

\begin{tabular}{|c|c|c|}
\hline \multirow{2}{*}{ Diagnosis } & \multicolumn{2}{|c|}{ Teenagers } \\
\hline & Number & Per cent. \\
\hline $\begin{array}{l}\text { Normal cervix, pelvis, and pseudo-erosion } \\
\text { Acute cervicitis (including those with } \\
\text { vaginitis and trichomoniasis) } \ldots \\
\text { Chronic cervicitis (including severe erosion) } \\
\text { Pelvic inflammatory disease } \\
\text { Pregnancy (including those with cervicitis) } \\
\text { Miscellaneous } \\
\text { Moniliasis (4) } \\
\text { Vaginitis and condylomata (2) } \\
\text { Bartholin's cyst (1) } \\
\text { Refused examination (1) } \\
\text { Healed chancroid (1) }\end{array}$ & $\begin{array}{r}70 \\
16 \\
44 \\
7 \\
9 \\
9\end{array}$ & $\begin{array}{r}45 \cdot 1 \\
10 \cdot 3 \\
28 \cdot 4 \\
4 \cdot 5 \\
5 \cdot 8 \\
5 \cdot 8\end{array}$ \\
\hline Total & 155 & \\
\hline
\end{tabular}

the cervix showed so-called "pseudo-erosion" or ectopy of the endocervical epithelium. This condition (Goldstein, 1955b) is ordinarily seen in 10 to 15 per cent. of young women, mostly in the nulliparous, and is held to be a normal finding by many gynaecologists. Acute or chronic cervicitis was the most common lesion found, comprising 61 cases (38.7 per cent.). There were also seven cases (4.5 per cent.) of chronic pelvic inflammation with adnexal masses.

Pelvic Lesions in Mature Contacts.-In 105 (27.4 per cent.) contacts, no gross pelvic lesions were discovered (Table IV). As in the younger group, there was a big percentage of chronic cervicitis (36 per cent.). The incidence of $11 \cdot 2$ per cent. of chronic pelvic inflammatory disease in these patients is more than double the percentage found in the adolescents. Altogether 21 (5.4 per cent.) women were pregnant. Myomata, retroversion, post-operative menopause, and ovarian cysts, as would be expected, were also found more commonly in the older women.

\section{TABLE IV}

PELVIC CONDITIONS IN ADULTS

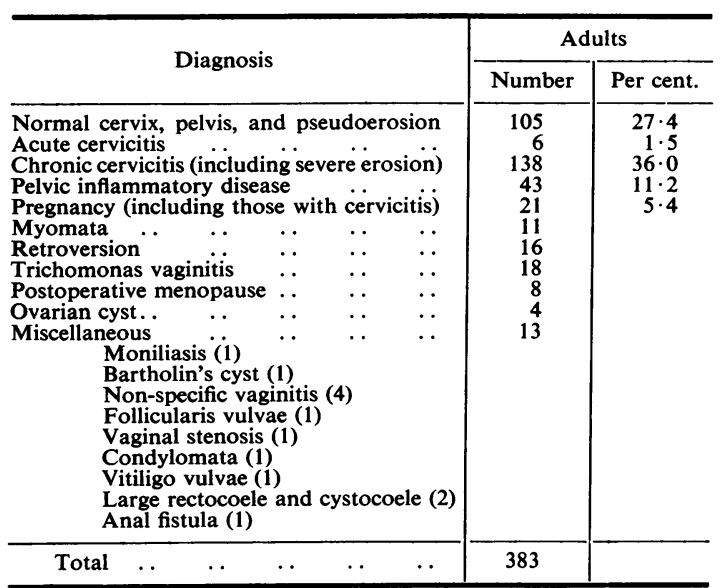

Gynaeocological Conditions with Proved Gonorrhoea.-The incidence of gonococcal infection according to the gynaecological conditions is shown in Table V (opposite). Of striking interest is the isolation of the specific organism from thirteen $(7 \cdot 4$ per cent.) patients in whom the cervix appeared normal. Davidson and Shepard (1948) also reported the presence of gonorrhoea in one-third of suspected cases where no discharge suggestive of the disease existed.

Of 22 cases of acute cervicitis, sixteen $(72 \cdot 7$ per cent.) were gonococcal in origin. The organism was 
TABLE V

PELVIC CONDITIONS WITH PROVED GONORRHOEA

\begin{tabular}{|c|c|c|c|}
\hline Conditions & $\begin{array}{l}\text { No. of } \\
\text { Cases }\end{array}$ & Positive & $\begin{array}{l}\text { Per } \\
\text { cent. }\end{array}$ \\
\hline 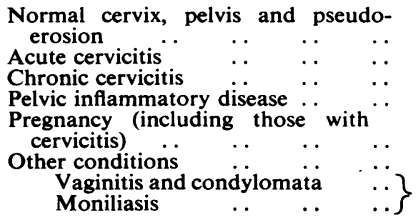 & $\begin{array}{r}175 \\
22 \\
182 \\
50 \\
\\
30 \\
79\end{array}$ & $\begin{array}{r}13 \\
16 \\
55 \\
18 \\
6 \\
2 \\
1\end{array}$ & $\begin{array}{r}7 \cdot 4 \\
72 \cdot 7 \\
30 \cdot 2 \\
36 \cdot 0 \\
20 \cdot 0 \\
3 \cdot 8\end{array}$ \\
\hline Total & 538 & 111 & \\
\hline
\end{tabular}

also recovered from $55(30 \cdot 2$ per cent.) cases in which the cervix was chronically inflamed. Six of thirty pregnant cases ( 20 per cent.), but only three (3.8 per cent.) of 79 contacts with gynaecological abnormalities (Tables III and IV) yielded the gonococcus.

The pelvic lesions in teen-agers and adults with bacteriological evidence of gonorrhoea are compared in Fig. 3. That the clinically normal cervix (including pseudo-erosion) may harbour the gonococcus is seen in the thirteen cases of gonorrhoea diagnosed solely by bacteriologic tests. However, minute pathological changes are probably produced

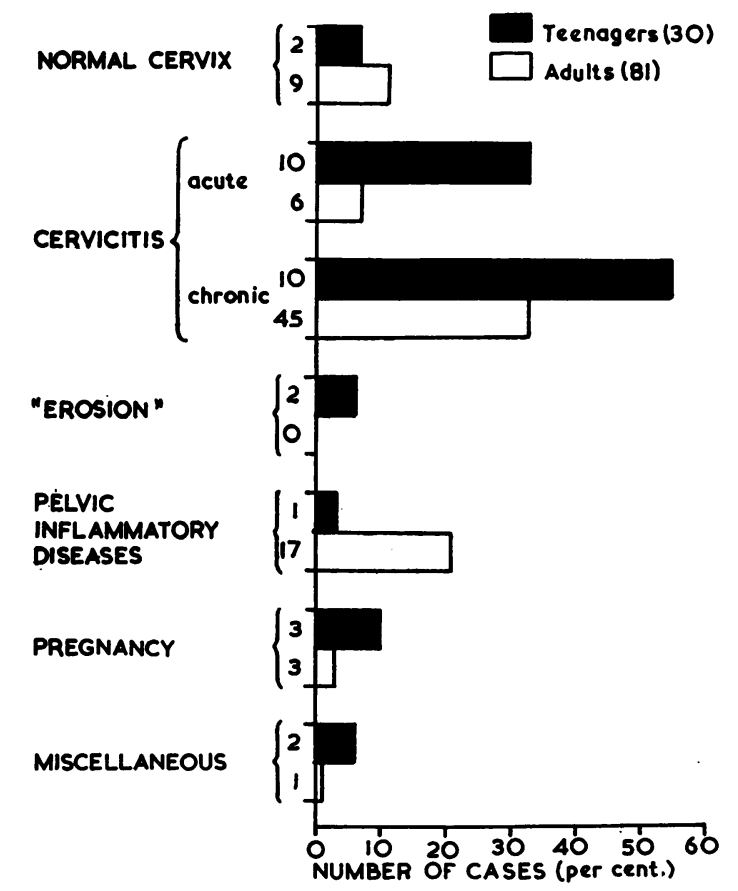

Fig. 3.-Comparison of pelvic lesions in thirty teen-agers and 81 adults with gonorrhoea. in the cervical tissues by invading gonococci. Onethird of the adolescents had an acute cervicitis as compared with only 7.4 per cent. in the infected adults. The cervicitis was almost always associated with an acute purulent vaginitis in the teen-agers.

The percentage of chronic cervicitis was much higher in the infected adults than in the younger patients. Only one teen-ager had developed pelvic complications which were rather frequent in the adults (21 per cent.), perhaps because in teen-agers infections were acute and received earlier recognition and eradication.

\section{Treatment}

All identified sexual contacts of men with clinical signs of gonorrhoea, as mentioned earlier, were treated with one intra-muscular injection of $1 \cdot 2$ million units aqueous penicillin. Those with bacteriological evidence of gonorrhoea received a second dose at their next visit to the clinic. Patients who were possibly allergic to this antibiotic were given $0.5 \mathrm{~g}$. streptomycin. Further treatment depended on the results of repeated cervical cultures. Since early in 1955, procaine penicillin G in oil has been used instead of the aqueous preparation. The cervicitis and vaginitis improved greatly in all cases, especially in those known to be caused by the gonococcus. There was also a noticeable reduction in the amount of purulent discharge in most of these patients either with "verified" or "unverified" gonorrhoea. Penicillin therapy had little effect on chronic inflammatory disease, although the local condition of the cervix was improved and the discharge became less purulent. Three patients with gonorrhoea, who were also suspected to be contacts of primary syphilis, were treated with streptomycin to avoid any "masking" effect of penicillin on syphilis. Any contact, regardless of the bacteriological findings, in whom a major pathological pelvic disease was discovered, or in whom the cervix required further treatment such as biopsy or conization, was referred to her physician or to a clinic. As a result of this procedure early carcinoma was discovered (stage 0 and stage 1) in two patients referred for biopsy of the cervix.

\section{Comment}

Analysis of the data collected on the teen-aged sexual contacts discloses the large proportion of unmarried girls (135 or 87 per cent.). Remarkable also is the incidence of pregnancies and abortions among the unmarried girls. The intimate relationship between venereal disease in teen-agers and illegitimate pregnancies, inclination to crime, and 
other socio-economic problems has now been generally recognized.

Gonococcal infection in the female may be suspected by the symptoms and abnormalities found on pelvic examination. The diagnosis, no doubt, may be prompted further if a history is obtained of a recent exposure to a male known to have gonorrhoea. Although pelvic inflammation, acute or chronic cervicitis, and purulent leucorrhoea are known to be caused by the gonococcus, bacteriological evidence is necessary to establish the final diagnosis.

That the clinically normal cervix may be infected is shown by the isolation of the gonococcus in thirteen cases in which the cervix was apparently healthy. For this reason, it is essential that bacteriological tests should be performed, especially if exposure to gonorrhoea is suspected, in order not to overlook the existence of this infection.

Although the stained smear disclosed the infection in 66 actual contacts of gonorrhoea (Table II), it is of little value as a routine in general practice. The routine use of urethral and cervical smears to detect the gonococcus has been eliminated in many obstetrical and gynaecological clinics because many cases of gonorrhoea were missed. The cultural method is universally recognized as the best procedure now available for the diagnosis of gonorrhoea. However, its value is only in direct ratio to the efficiency of the media, and to the technical skill and diagnostic acumen of the bacteriologist. The low percentage of positive cultures (16 per cent.) in the series of cases reported is at least partially caused by the time lost in transporting the inoculated tubes of media to the central laboratory. High percentages of positive Neisserian cultures from women of the kind studied here have been reported by Cohn and Grunstein (1944), Somerson and others (1955), and Braff (1956), and other workers.

It is difficult to compare accurately the incidence of gonorrhoea in female contacts as reported in the literature, because in some reports the percentages of the males with "verified" gonorrhoea are not given. In one large venereal disease control clinic in Philadelphia, the incidence of gonorrhoea in the male as determined by stained smear is about 90 per cent.

Many factors operate in obtaining bacteriological proof of gonorrhoea in women, such as lapse of time from the drawing of the specimens of discharge until its actual spreading on culture medium, additional supportive procedures, and, finally, the degree of accuracy of the final microscopic examination. There were a few cases of acute cervicitis and pelvic inflammatory disease in some alleged sexual contacts of gonorrhoea clinically very suggestive of gonococcal infection, yet the cultures did not produce the organisms.

Acute cervicitis with its associated purulent vaginitis in teen-agers with a history of contact with gonorrhoea is often caused by the gonococcus. The culture was positive in over two-thirds of the cases of acute cervicitis in this study. Occasionally, the purulent vaginitis was found to be associated also with trichomonal infection. Pelvic inflammatory complications are observed less often in teen-agers than in adults because the acute symptoms bring them to the clinic for diagnosis and treatment before complications set in. Procrastination in starting treatment and re-infection are likely reasons for the greater number of cases of chronic pelvic inflammatory disease in adults.

\section{Summary}

Pelvic examinations and laboratory tests were performed on teen-aged girls and older females who were the alleged sexual contacts of men treated for acute urethritis. Altogether 85 to 90 per cent. of these men were proved by smear to have gonorrhoea. There were $155(28.8$ per cent.) teen-agers and 383 women. Of the teen-agers, 87 per cent. were unmarried and 21.4 per cent. admitted pregnancies.

Positive laboratory evidence of gonorrhoea by culture and/or smear was obtained in thirty teenagers and in 81 females over the age of 19. The overall incidence of proved gonorrhoea was $20 \cdot 6$ per cent.

The gynaecological abnormalities detected in both groups of contacts are described. Similar conditions were found in both groups, except that, as would be expected, myomata, retroversion, postoperative menopause, and ovarian cysts were confined entirely to the group of mature women.

The pathological alterations in the genital tract with positive evidence of gonorrhoea are described. The gonococcus was isolated from thirteen $(7 \cdot 4$ per cent.) of 175 patients with a clinically normal cervix. The predilection of the gonococcus for the cervix, causing acute and chronic cervicitis, is noted. Laboratory evidence of gonorrhoea was obtained in twenty ( 33.3 per cent.) out of sixty cases of cervicitis among the contacts. The value of the culture in the microscopic detection of acute and chronic cervicitis is emphasized.

The gonococcus was most often found in teenagers with acute cervicitis $(62 \cdot 5$ per cent.). Chronic cervicitis and pelvic complications were more common in infected adults. There was only one case of pelvic inflammation among the teen-agers but 
there were seventeen ( 21 per cent.) cases in the mature women. Six pregnant women were found to have gonorrhoea.

All alleged or named contacts were treated with $1 \cdot 2$ million units penicillin to prevent the spread of venereal disease. The therapeutic usefulness of antibiotics is noted.

\section{REFERENCES}

Braff, E. H. (1956). Personal communication. San Francisco City Clinic, San Francisco, California.
Carpenter, C. N., Bucca, M. A., Buck, T. C., Casman, E. P., Christensen, C. W., Crowe, E., Drew, R., Hill, J., Lankford, C. E., Morton, H. E., Peizer, L. R., Shaw, C. I., and Thayer, J. D.' (1949). Amer. J. Syph., 33, 164.

Cohn, A., and Grunstein, I. (1944). Amer. J. Obstet. Gynec., 48, 339. Davidson, H. H., and Shepard, M. C. (1948). J. vener. Dis. Inform., 29, 332.

Donohue, J. F., Gleeson, G. A., Jenkins, K. H., and Price, E. V. (1955). Pub. Hlth Rep. (Wash.), 70, 453

Goldstein, L. Z. (1955a). Obstet. Gynec., 6, 193.

(1955b). Seminar, 17, No. 3, pp. 9, 13 .

Lentz, J. W., and Beerman, H. (1953). Amer. J. Syph., 37, 427.

Somerson, N. L., Rubin, A., Smith, P. F., and Morton, H. E. (1955). Amer. J. Obstet. Gynec., 69, 848. 